\title{
UREA REBOUND - SOME DISADVANTAGES OF UREA KINETIC MODELING
}

\author{
Alexander Stoyanov, Krasimira Nenova, Kiril Nenov \\ Department of Internal Medicine, Medical University of Varna
}

\begin{abstract}
PURPOSE: The objectives of the present study are to determine the average urea rebound by examining the urea concentrations immediately after completion of hemodialysis (HD) and comparing these results to urea concentrations taken $30 \mathrm{~min}$ after the procedure (equilibrated values), to assess how the delivered dialysis dose changes when URR and $\mathrm{Kt} / \mathrm{V}$ are calculated using each of these two values and to evaluate the significance of these differences and the reliability of the indicators in use.
\end{abstract}

MATERIAL AND METHODS: The study covered 30 end-stage renal failure (ESRF) patients, 16 males and 14 females on chronic HD at a mean age of $43,90 \pm 10,63$ years and average duration of dialysis treatment of $6,90 \pm 3,75$ years. Average urea values were calculated for each patient using data from three consecutive monthly examinations taken immediately and $30 \mathrm{~min}$ after HD in order to determine the mean urea rebound percentage.

RESULTS: Mean urea values in samples taken immediately and 30 min after HD showed statistically significant differences $(p<0,05)$. Equilibrating urea concentration led to an average increase of $17,7 \%$ at the $30^{\text {th }}$ min after HD. There was a statistically significant difference $(p<0,05)$ between the calculated single pool $\mathrm{Kt} / \mathrm{V}(1,23 \pm 0,11)$ and equilibrated $\mathrm{Kt} / \mathrm{V}(1,17 \pm 0,18)$ as well as concerning mean URR values calculated by using non-equilibrated and equilibrated post dialysis urea $(65,3 \pm 1,18 \%$ and $6,67 \pm 2,4 \%$, respectively).

CONCLUSION: Calculation of URR and single pool model of $\mathrm{Kt} / \mathrm{V}$ for assessment of dialysis adequacy in ESRF patients on chronic HD results in overestimation of the delivered dialysis dose. These values differ statistically significantly from those when accounting for urea rebound. URR and Kt/Vsp indicators do not possess the necessary reliability as means to evaluate the delivered dialysis dose.

Key words: dialysis adequacy, dialysis dose, urea rebound, urea kinetic modeling, chronic hemodialysis

\section{INTRODUCTION}

The issues of dialysis adequacy are of rising medical and economic importance (6). The necessity of estimating the individual dialysis dose of patients

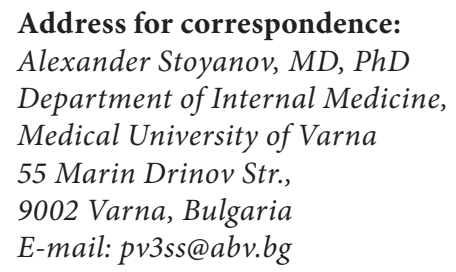

Received: December 4, 2012

Accepted: January 15, 2013 on periodic hemodialysis (HD) presents with two aspects. First comes the wish to achieve maximal blood purification and thus a reduced morbidity and mortality rates. Second come the economic realities influencing on quality and duration of $\mathrm{HD}$ as this is an extraordinarily expensive therapy. Urea kinetic modelling and parameters of dialysis adequacy are widely used worldwide although often criticized nowadays $(13,14)$.

According to the recommendation of Bulgarian medical standard of 'Dialysis treatment', a urea reduction ratio (URR) $>65 \%$ or $\mathrm{Kt} / \mathrm{V}>1,2$ for every $\mathrm{HD}$ procedure (three times weekly) should be achieved in $85 \%$ of the patients after three months of HD. HD

Scripta Scientifica Medica, 2013, vol. 45 (1), pp. 71-74

Copyright (C) Medical University - Varna 
effectiveness (URR and Kt/V) should be estimated every three to four months.

Determination of the dialysis dose is usually performed by using URR and single pool model of $\mathrm{Kt} / \mathrm{V}$. Urea rebound after $\mathrm{HD}$ is determined as a rapid reverse increase of blood urea concentration resulting from its liberation from cells, tissues and organs where it exists in higher concentrations (9). Urea increases between $15 \mathrm{~min}$ and one hour after $\mathrm{HD}$ completion with a maximal value at $30^{\text {th }} \mathrm{min}$ (Fig. 1).

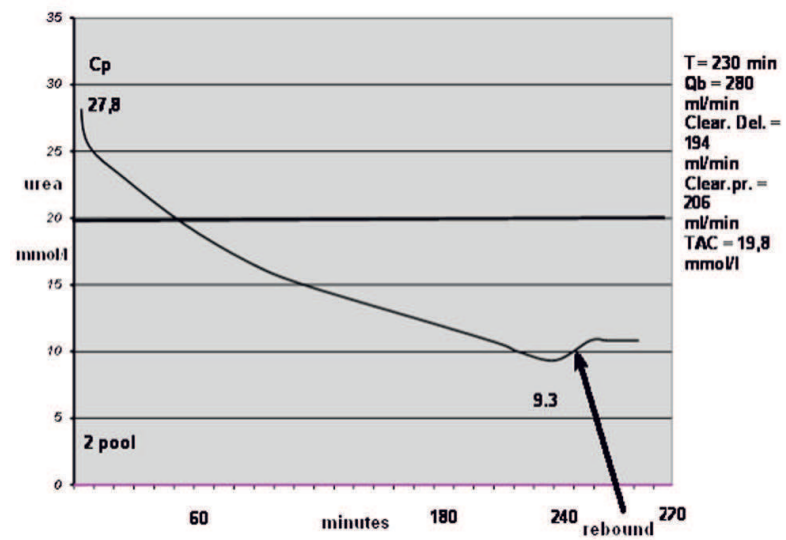

Fig. 1. Urea rebound - patient D. K., double pool model (UKM software MEDISC - Germany).

The objectives of the present study are to determine the average urea rebound by examining the urea concentrations immediately after completion of hemodialysis (HD) and comparing these results to urea concentrations taken $30 \mathrm{~min}$ after the procedure (equilibrated values), to assess how the delivered dialysis dose changes when URR and Kt/V are calculated using each of these two values and to evaluate the significance of these differences and the reliability of the indicators in use.

\section{MATERIAL AND METHODS}

The study covered 30 end-stage renal failure (ESRF) patients, 16 males and 14 females on chronic

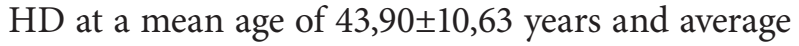
duration of dialysis treatment of $6,90 \pm 3,75$ years. The vascular access was AV fistula in 24 patients and a permanent vascular catheter in 6 ones. Qb was between 220 and $350 \mathrm{mLl} / \mathrm{min}$. Dialysis apparatuses
Fresenius, series 4008 and bicarbonate buffer were used. Qd was $500 \mathrm{~mL} / \mathrm{min}$. HD was performed three times weekly, with heparinization bolus in the beginning of the procedure and with a mean duration time of $10,42 \pm 1,25$ hours. Disposable capillary dialyzers with polysulphonic membrane were applied. Dialysis dose was calculated by using an own software (10) and MEDIX software from Germany.

The examinations were performed monthly for three months in all the patients. Mean urea values were calculated from three weekly measurements immediately and $30 \mathrm{~min}$ after HD. Besides the mean urea rebound percentage was calculated. By means of urea kinetic modelling, a total of 90 estimations of the indicators of dialysis adequacy such as Kt/ Vsp prescr., Kt/Vsp deliv., Kt/Vdp and URR were performed in all the patients. Blood samples were taken according to NKF-KDOQI Clinical Practice Guidelines for Hemodialysis Adequacy $(7,11)$.

\section{RESULTS}

Mean urea values in samples taken immediately and $30 \mathrm{~min}$ after HD showed statistically significant differences $(\mathrm{p}<0,05)$. Equilibrating urea concentration led to an average increase of $17,7 \%$ at the $30^{\text {th }} \mathrm{min}$ after HD (Table 1). The calculations by means of urea kinetic modelling of MEDIX software and of our own software showed that $\mathrm{Kt} / \mathrm{Vsp}=1,22 \pm 0,02$ and Kt/ $\mathrm{Vsp}=1,23 \pm 0,11$. There was no statistically significant difference between both methods $(\mathrm{p}=0,329 ; \mathrm{n}=30)$

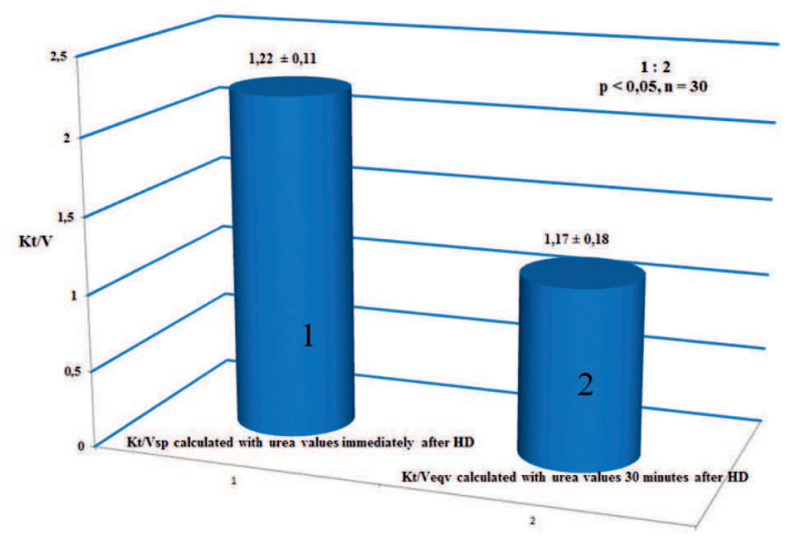

Fig. 2. Difference between mean values of $U R R$ and URRequ $(1: 2, p<0,5, n=30)$ 
Table 1. Mean urea values from three examinations immediately and 30 min after $H D$ and mean urea rebound percentage in 30 patients on chronic $H D$

\begin{tabular}{|c|c|c|c|}
\hline $\begin{array}{l}\text { Patient } \\
\text { No }\end{array}$ & $\begin{array}{l}\text { Mean urea } \\
\text { values } \\
\text { immediately } \\
\text { after HD } \\
(\mathrm{mmol} / \mathrm{L})\end{array}$ & $\begin{array}{l}\text { Mean urea } \\
\text { values } \\
30 \mathrm{~min} \\
\text { after HD } \\
(\mathrm{mmol} / \mathrm{L})\end{array}$ & $\begin{array}{c}\text { Mean } \\
\text { percentage } \\
\text { of urea } \\
\text { rebound }\end{array}$ \\
\hline 1 & 13,4 & 15,8 & 18 \\
\hline 2 & 11,3 & 13,2 & 17 \\
\hline 3 & 8,1 & 10 & 23 \\
\hline 4 & 13,9 & 15,6 & 12 \\
\hline 5 & 8,3 & 9,8 & 18 \\
\hline 6 & 10 & 11,3 & 13 \\
\hline 7 & 11 & 12,8 & 16 \\
\hline 8 & 12 & 14,3 & 19 \\
\hline 9 & 11 & 13,7 & 25 \\
\hline 10 & 13,5 & 15 & 11 \\
\hline 11 & 12,7 & 14,6 & 15 \\
\hline 12 & 9,9 & 11,8 & 19 \\
\hline 13 & 7,3 & 9,1 & 25 \\
\hline 14 & 12,9 & 14,8 & 15 \\
\hline 15 & 10,9 & 12,6 & 16 \\
\hline 16 & 6,3 & 8 & 27 \\
\hline 17 & 13,8 & 16,5 & 20 \\
\hline 18 & 9 & 11,3 & 26 \\
\hline 19 & 17 & 18,9 & 11 \\
\hline 20 & 12,8 & 14,7 & 15 \\
\hline 21 & 13,9 & 15,6 & 12 \\
\hline 22 & 8,3 & 9,8 & 18 \\
\hline 23 & 10 & 11,3 & 13 \\
\hline 24 & 11 & 12,8 & 16 \\
\hline 25 & 12 & 14,3 & 19 \\
\hline 26 & 13,5 & 15,9 & 18 \\
\hline 27 & 12,7 & 14,6 & 15 \\
\hline 28 & 9,9 & 11,8 & 19 \\
\hline 29 & 7,3 & 9,1 & 25 \\
\hline 30 & 12,9 & 14,8 & 15 \\
\hline \multirow[t]{2}{*}{ Mean \pm SD } & $11,22 \pm 2,47$ & $13,13 \pm 2,60$ & $17,7 \pm 4,5$ \\
\hline & 1 & 2 & \\
\hline
\end{tabular}

while a high positive correlation was proved $(\mathrm{r}=0,975$; $\mathrm{p}<0,01 ; \mathrm{CI}=95 \%, \mathrm{n}=60)$. Concerning the equilibrated urea values $30 \mathrm{~min}$ after $\mathrm{HD}$, the difference after the calculation of $\mathrm{Kt} / \mathrm{Veqv}=1,17 \pm 0,18$ was statistically significant $(\mathrm{p}<0,05)$ (Fig. 2). The similar relations were established concerning the mean URR values obtained by means of non-equilibrated and equilibrated post-dialysis urea (Fig. 3). There was a statistically significant difference $(p<0,05)$ between the calculated single pool Kt/V $(1,23 \pm 0,11)$ and equilibrated Kt/V $(1,17 \pm 0,18)$.

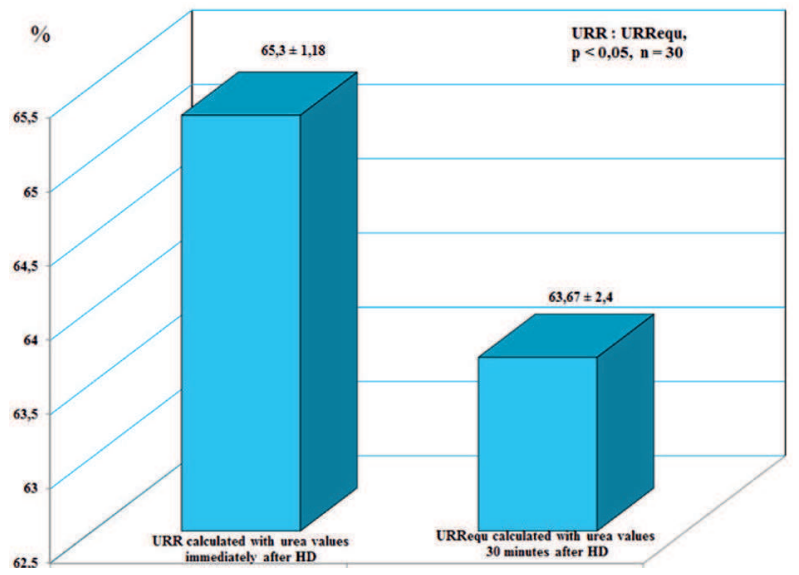

Fig. 3. Difference between mean values of Kt/Vsp and $\mathrm{Kt} / \mathrm{Vequ}(1: 2, p<0,5, n=30)$

\section{DISCUSSION}

Rendering an account of single body pools is of importance when defining urea concentration and kinetics. The presence of such pools in the organism reduces the effectiveness of the extraction of uremic toxins localized there and induces rebound during which urea reaches its maximal value about $30 \mathrm{~min}$ after HD completion.

Disadvantages of single pool model (Kt/Vsp) can be corrected through the double pool model or an equilibrated parameter of dialysis adequacy (Kt/ Vequ).

Real-time monitoring of urea concentration occupies a leading position in the quantitative determination of dialysis dose $(1,2,5)$. The differences of the urea values of the blood and dialysis end of the monitor enable the easy calculation of the standard urea kinetic parameters (4). 
Estimmation of ultraviolet-absorbance, blood urea, dialysate urea and ionic dialysance is used as clearance variation sensitivity $(1,12)$.

Recently, a lot of publications dealing with the significant aspects of urea rebound (8) and urea kinetic modeling occur in the world literature available (3). Further comprehensive research is needed to elucidate in more detail these controversial issues.

\section{CONCLUSION}

Calculation of URR and single pool model of $\mathrm{Kt} / \mathrm{V}$ for assessment of dialysis adequacy in ESRF patients on chronic HD results in overestimation of the delivered dialysis dose. These values differ statistically significantly from those when accounting for urea rebound. URR and Kt/Vsp indicators do not possess the necessary reliability as means to evaluate the delivered dialysis dose.

\section{REFERENCES}

1. Castellarnau, A., M. Werner, P. Günthner, M. Jakob. Real-time Kt/V determination by ultraviolet absorbance in spent dialysate: technique validation.- Kidney Int., 78, 2010, No 9, 920-925.

2. Castro, M. C., J. E. Romao, Jr, M. Marcondes. Measurement of blood urea concentration during haemodialysis is not an accurate method to determine equilibrated post-dialysis urea concentration.- Nephrol. Dial. Transplant., 16, 2001, No 9, 1814-1817.

3. Daugirdas, J. T. Hemodialysis adequacy and biocompatibility.- Semin. Dial., 24, 2011, No 5, 508-509.

4. Ficheux, A., N. Gayrard, I. Szwarc, S. Soullier, J. Bismuth-Mondolfo, P. Brunet, M. Servel, A. Argilés. Use of spent dialysate analysis to estimate blood levels of uraemic solutes without blood sampling: urea.- Nephrol. Dial. Transplant., 25, 2010, No 3, 873-879.
5. Lindley, E. J., P. W. Chamney, A. Wuepper, H. Ingles, J. E. Tattersall, E. J. Will. A comparison of methods for determining urea distribution volume for routine use in on-line monitoring of haemodialysis adequacy.- Nephrol. Dial. Transplant., 24, 2009, No 1, 211-216.

6. Lindsay, R. M., J. Sternby. Future directions in dialysis quantification.- Semin. Dial., 14, 2001, No 4, 300-307.

7. NKF-KDOQI. Clinical practice guidelines for hemodialysis adequacy. New York, National Kidney Foundation, 2006.

8. Schneditz, D., J. T. Daugirdas. Compartment effects in hemodialysis.- Semin. Dial., 14, 2001, No 4, 271-277.

9. Stoyanov, A. Reasons for dialysis adequacy failure.Annu. Proc. IMAB, 2, 2000, 200-201.

10. Stoyanov, A., P. Tchankova. Original PC program for determination of the dialysis dose and nutritional status of patients on chronic hemodialysis.- Scr. Sci. Med. (Varna), 32, 2000, 75-78.

11. Traynor, J. P., C. C. Geddes, C. Ferguson, R. A. Mactier. Predicting 30-minute postdialysis blood urea concentrations using the stop dialysate flow method.- Am. J. Kidney Dis., 39, 2002, No 2, 308-314.

12. Uhlin, F., I. Fridolin, M. Magnusson, L. G. Lindberg. Dialysis dose (Kt/V) and clearance variation sensitivity using measurement of ultraviolet-absorbance (on-line), blood urea, dialysate urea and ionic dialysance.- Nephrol. Dial. Transplant., 21, 2006, No 8, 2225-2231.

13. Vanholder, R. C., R. V. De Smet, S. M. Ringoir. Assessment of urea and other uremic markers for quantification of dialysis adequacy.- Clin. Chem., 38, 1992, No 8, Pt.1, 1429-1436.

14. Vanholder R., R. DeSmet, G. Lesaffer. Dissociation between dialysis adequacy and Kt/V.- Semin. Dial., 15, No 1, 2002, 3-7. 